\title{
Survival and Side Effects in Non-Small Cell Lung Cancer Patients Treated With Combination of Chemotherapy and Conformal Radiotherapy
}

\author{
Simonida Crvenkova* \\ University Clinic of Radiotherapy and Oncology, Faculty of Medicine, Ss Cyril and Methodius University of Skopje, Skopje, \\ Republic of Macedonia
}

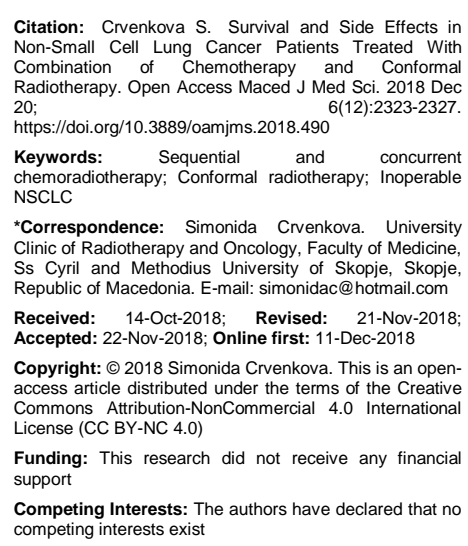

competing interests exist

\begin{abstract}
BACKGROUND: Combined modality therapy is standard of care for patients with inoperable locally advanced non-small cell lung cancer (NSCLC), however, insufficient data exist regarding what chemoradiotherapy combination will be the gold standard.

AIM: The study aimed to compare the survival impact and side effects of concurrent versus sequential radiochemotherapy treatment in inoperable stage III non-small cell lung cancer (NSCLC).

METHODS: To evaluate the treatment results and prognostic variables, $85 \mathrm{NSCLC}$ patients treated from October 2005 to November 2008 were randomly assigned to one of the two treatment arms. In the first arm (sequential arm), 45 patients received sequential chemotherapy with 4 cycles of carboplatin and etoposide followed by conformal 3-dimensional (3D) radiotherapy (RT). In the second arm (concurrent arm), 40 patients received concomitant chemotherapy with cisplatin and etoposide and conformal RT, followed by two cycles of consolidation chemotherapy with carboplatin and etoposide
\end{abstract}

RESULTS: The median survival was 13 months for the patients in the sequential arm and 19 months for those in the concurrent treatment arm $(p=0.0039)$. The disease-free survival (DFS) was 9 months in the sequential arm and 16 months in the concurrent treatment arm $(p=0.0023)$. Seven complete responses and 18 partial responses were obtained with sequential treatment. Twelve complete responses and 21 partial responses were obtained in concurrent arm. The differenced were statistically significant $p=0.03$. Median survival for patients with complete response in concurrent treatment arm was 36 months versus 18 mounts for a sequential arm; partial response was 27 months versus 16 months and those with stable disease 11 months versus 9 months. Treatment-related toxicities were assessed according to the RTOG/EORTC criteria. Acute esophagitis and incidence of neutropenia were higher with the concurrent than with sequential treatment. Grade 3 esophagitis was characteristic only for concurrent treatment, and it was the reason for radiotherapy interruption, but no longer than 7 days. Secondary anaemia was more frequent in the sequential treatment arm.

CONCLUSION: The statistically significant differences in survival were suggested that the concurrent chemotherapy and conformal three-dimensional radiotherapy is the optimal strategy for patients with locally advanced NSCLC with acceptable toxicity rates.

\section{Introduction}

Lung cancer remains a worldwide epidemic. Approximately 1.2 million people die from lung cancer each year. NSCLC patients represent more than $80 \%$ of all lung cancers. Of the patients with NSCLC, 60$70 \%$ present with Stage III or IV disease. In the late 1980 s, radiotherapy was the standard treatment for these patients [1]. Randomised trials and a 1995 overview subsequently showed that combination chemoradiotherapy was superior to radiotherapy alone [2]. Many chemotherapeutic agents active in NSCLC possess radiosensitising properties, thereby improving the probability of local control. Also, chemotherapy administered concurrently with thoracic radiation may act systemically and potentially eradicate distant micro-metastases. Several studies showed the feasibility of the cisplatin-etoposide combination plus radiotherapy for patients with stage III disease [3]. The primary endpoint on this study was the effect of sequential and concurrent chemoradiotherapy on overall survival. 


\section{Material and Methods}

This study was prospective, randomised and started in the Institute of Radiotherapy and Oncology in Skopje, October 2005. Eligible 85 patients were aged between 18 and 70 years, had an Eastern Cooperative Oncology Group (ECOG) Score $\leq 1$ and had $\leq 10 \%$ weight loss in 3 months before inclusion. They have previously untreated histological or cytological proven NSCLC, unrespectable stage IIIAN2 disease, or stage IIIB disease without pleural effusion. Stage IIIB disease was assigned either by N3 (contralateral mediastinal or supraclavicular nodes) or by T4 from the invasion of mediastinal structures. The following laboratory values were required: leucocytes $\geq 1.5 \times 10^{3} / /$, platelets $\geq 100 \times$ 10/l, AST and ALT $\leq 2 \times$ the upper limit of the referent rang. Ineligibility criteria were as follows: uncontrolled infection, or fever over $38^{\circ} \mathrm{C}$, unstable cardiovascular disease and previous malignancy.

Before enrollment, the patients gave their full medical histories and underwent a clinical examination with assessment of performance status (PS). Patients were randomly assigned to receive sequential or concurrent therapy. Patients were randomly assigned to receive sequential or concurrent therapy. In the sequential arm, 45 patients received four cycles of chemotherapy. They were administered first, consisting of carboplatin (AUC $\times 6$ ) on day 1 and etoposide on days 1-3, repeated every 3 weeks. The radiotherapy began 4 weeks after the fourth cycle of chemotherapy administration. Chemotherapy and radiotherapy began simultaneously in concurrent arm consisted of 40 patients. The first cycle of chemotherapy, with cisplatin $30 \mathrm{mg} / \mathrm{m}^{2}$ and etoposide $100 \mathrm{mg} / \mathrm{m}^{2}$ was administered on days 1 to 3 , and the second cycle of chemotherapy was administered the last 3 days of conformal radiotherapy, in concurrent arm. After 4 weeks of concurrent chemoradiotherapy schedule, two cycles of consolidation chemotherapy began, consisting of carboplatin (AUC $x \quad 6$ ) and etoposide $100 \mathrm{mg} / \mathrm{m}^{2}$ on day 1 to 3 .

Conformal radiotherapy at both arms consisted of 60 Gy in 30 fractions of 2 Gy per fraction, for 5 days a week given throughout 6 weeks. A treatment planning $C T$ was required to define the gross tumour volume (GTV). Each patient was positioned in an immobilisation device-wing board in the treatment position on a flat table. CT slices with 5 $\mathrm{mm}$ thickness were obtained starting from cricoid cartilage and extending inferiorly to the level of the L1 vertebral body. The GTV, clinical target volume (CTV), planning target volume (PTV) and normal organs were outlined on all CT slices. The normal tissues contoured included lungs (as the total lung volume), heart, spinal cord and oesophagus. The CTV included the entire GTV plus $0.7 \mathrm{~cm}$, and the PTV included CTV plus another $0.7 \mathrm{~cm}$ adding margin. PTV44 was treated with parallel-opposed anterior-posterior fields and PTV60 was treated with any combination of fields depends on spinal cord constrain. If radiotherapy had to be delayed for more than 7 days, the patient was withdrawn from the study.

In the sequential arm, responses were assessed 8 weeks after the end of radiotherapy. In the concurrent arm, responses were assessed 8 weeks after the end of the consolidation chemotherapy. Imaging studies x-ray and/or computed tomography (CT) could be repeated at all times when clinically indicated. Complete and partial responses were based on RECIST criteria. Toxicity was graded according to RTOG/EORTC criteria. Follow-up visits were conducted every 2 months during the first year and after that every 3 months. Patients with evidence of progression at any time were removed from the study but continued to be evaluated for survival and toxicity. Survival and the interval to recurrence or progression were measured from the date of the first treatment session.

\section{Results}

One hundred and ten patients were identified from our database. Of these, 25 were excluded from analysis: 7 had metastatic disease, 7 had sudden deterioration of their general condition, 3 patients had pleural effusion, loss of data or loss of any contact in 3 patients, and 5 patients due to delivered tumour dose less than 60 Gy. Eighty-five patients were subsequently included for further analyses. The characteristics of 85 patients are listed in Table 1.

Table 1: Patient and disease characteristics

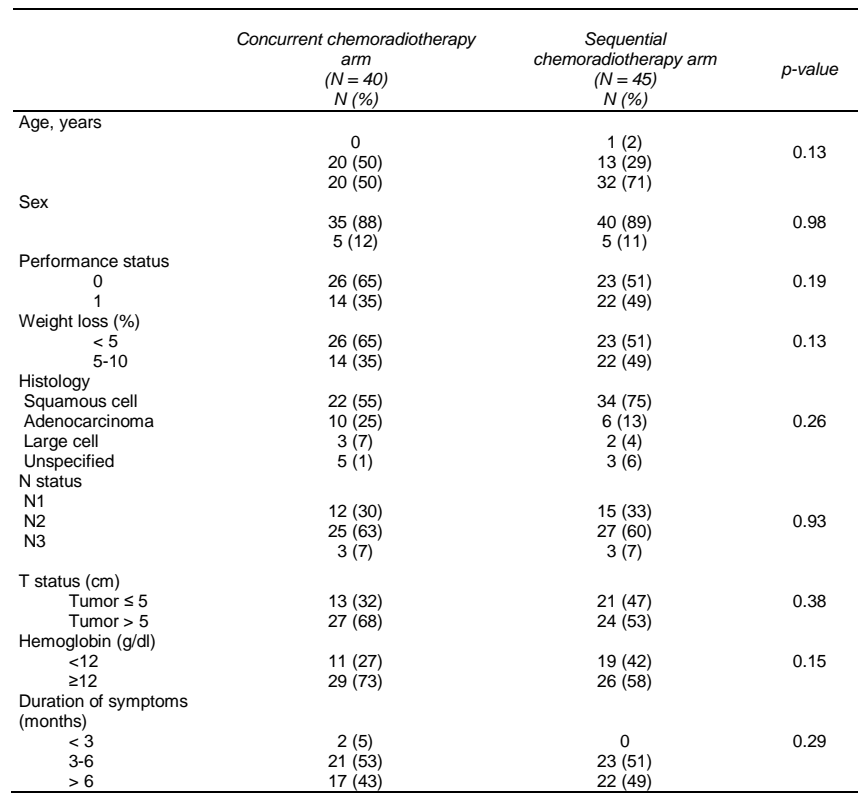

Survival was analysed until March 2010. The median OS was 13 months in the sequential arm 
(95\% Cl 10.2-15.7), and 19 months in the concurrent treatment arm $(95 \% \mathrm{Cl} 13.6-24.3)$, with statistically significant difference (log-rank test, $p=0.0039$; Figure 1).

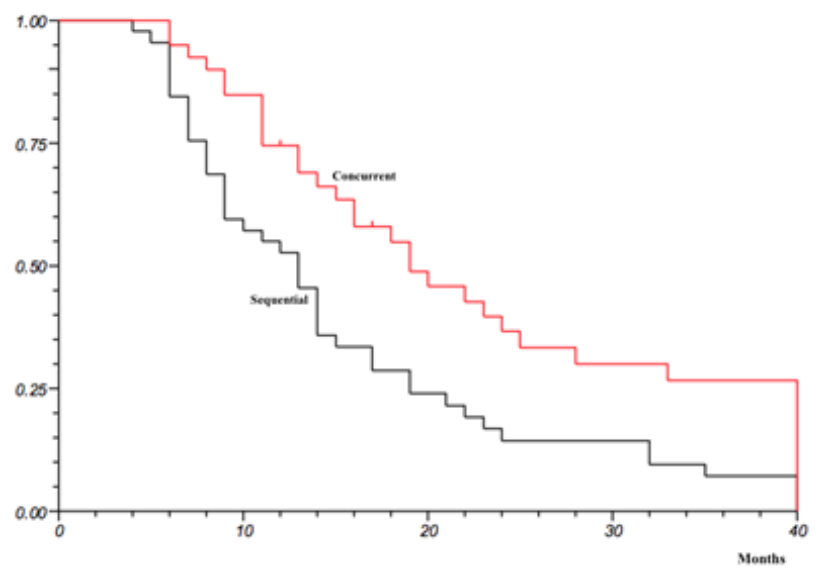

Figure 1: Overall survival according to the treatment arm ( $p=$ 0.0039)

The 1, 2 and 3-year OS rates were 74, 36 and $27 \%$ in the concurrent arm and 52,14 and $7.1 \%$ in the sequential arm $(p=0.0039)$. DFS for the concurrent arm was 16 months $(95 \% \mathrm{Cl} 12.7-19.2)$, and for the sequential arm, it was 9 months $(95 \% \mathrm{Cl} 5.8-12.16)$. The difference was statistically significant (log-rank test, $p=0.0023$; Figure 2).

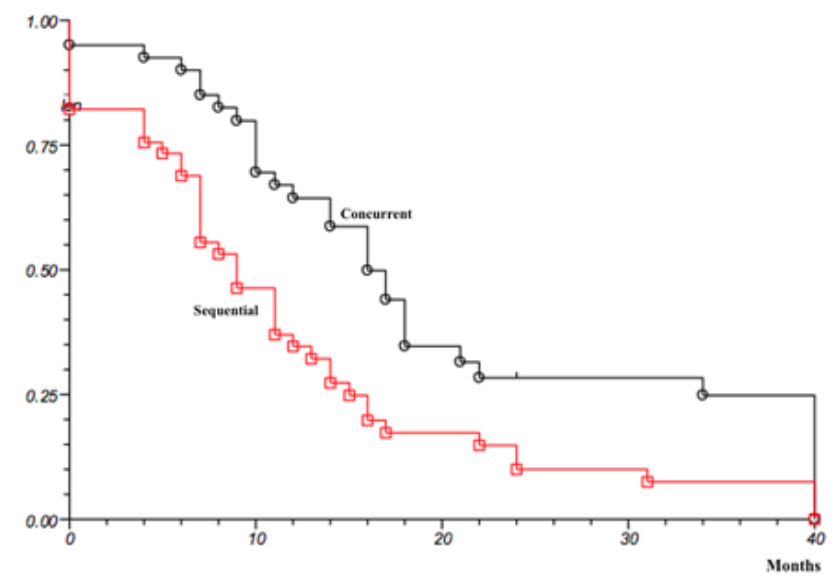

Figure 2: Disease-free survival according to the treatment arm ( $p=$ 0.0023)

Survival time was insignificant correlation with local tumor control $(p<0,001)$. Local tumour response was evaluated for each patient included in the study (Table 2). Seven patients with complete response and 18 with partial responses were obtained treated with sequential treatment. Twelve patients with complete response and 21 with partial response were obtained in the concurrent treatment arm. According to tumour responses, the difference between treatment arms was statistically significant $p=0.03$. Median survival for patients with complete response in concurrent treatment arm was 36 months versus 18 months in sequential arm. Median survival for patients with partial response in the concurrent arm was 27 months versus 16 mounts in sequential arm and for those patients with stable disease median survival was 11 months in concurrent arm versus 9 months in the sequential treatment arm.

Table 2: Tumor response in concurrent and sequential treatment arm

\begin{tabular}{lcccccc}
\hline $\begin{array}{l}\text { Treatment } \\
\text { arm }\end{array}$ & $\begin{array}{c}\text { CR } \\
\text { Complete } \\
\text { response }\end{array}$ & $\begin{array}{c}\text { PR } \\
\text { Partial } \\
\text { response }\end{array}$ & $\begin{array}{c}\text { CR + PR } \\
\text { Objective } \\
\text { response }\end{array}$ & $\begin{array}{c}\text { SD } \\
\text { Stabile } \\
\text { disease }\end{array}$ & $\begin{array}{c}\text { NR No } \\
\text { response }\end{array}$ & Patients \\
\hline $\begin{array}{l}\text { Concurrent } \\
\text { arm }\end{array}$ & $12(30 \%)$ & $21(53 \%)$ & $33(83 \%)$ & $3(7 \%)$ & $4(10 \%)$ & 40 \\
$\begin{array}{l}\text { Sequentional } \\
\text { arm }\end{array}$ & $7(16 \%)$ & $18(40 \%)$ & $25(56 \%)$ & $12(27 \%)$ & $8(18 \%)$ & 45 \\
& $19(22 \%)$ & $39(46 \%)$ & $58(68 \%)$ & $15(18 \%)$ & $12(14 \%)$ & $85(100 \%)$ \\
\hline$p=0.04573 ;$ SS $=3 ; \mathrm{x}^{2}=8.01350$. & & & &
\end{tabular}

Prognostic factors with a significant influence on survival were: initial performance status according to ECOG, initial weight loss, nodal involvement, tumour size and ages. Prognostic factors without any influence on survival were: gender, duration of symptoms, haemoglobin level and histological type.

Table 3: Treatment toxicity according to RTOG/EORTG criteria in sequential arm and concurrent arm

\begin{tabular}{|c|c|c|c|c|c|c|c|c|c|}
\hline \multicolumn{2}{|c|}{ Treatment toxicity } & \multicolumn{4}{|c|}{ Sequential arm } & \multicolumn{4}{|c|}{ Concurrent arm } \\
\hline & & $\begin{array}{c}\text { Grade } \\
0 \\
9\end{array}$ & $\begin{array}{c}\text { Grade } \\
1 \\
\end{array}$ & \multirow{2}{*}{$\begin{array}{c}\text { Grade } \\
2 \\
10 \\
(22 \%)\end{array}$} & \multirow{2}{*}{$\begin{array}{c}\text { Grade } \\
3 \\
2 \\
(4 \%)\end{array}$} & \multirow{2}{*}{$\begin{array}{c}\text { Grade } \\
0 \\
3 \\
(8 \%)\end{array}$} & \multirow{2}{*}{$\begin{array}{c}\begin{array}{c}\text { Grade } \\
1\end{array} \\
24 \\
\end{array}$} & \multirow{2}{*}{$\begin{array}{c}\text { Grade } \\
2 \\
8 \\
(20 \%)\end{array}$} & \multirow{2}{*}{$\begin{array}{c}\text { Grade } \\
3 \\
5 \\
(13 \%)\end{array}$} \\
\hline Early & Lungs & $\begin{array}{c}9 \\
(20 \%)\end{array}$ & $\begin{array}{c}24 \\
(53 \%)\end{array}$ & & & & & & \\
\hline & Esophagus & $\begin{array}{c}17 \\
(38 \%)\end{array}$ & $\begin{array}{c}20 \\
(44 \%)\end{array}$ & $\begin{array}{c}8 \\
(18 \%)\end{array}$ & 0 & $\begin{array}{c}2 \\
(5 \%)\end{array}$ & $\begin{array}{c}20 \\
(50 \%)\end{array}$ & $\begin{array}{c}15 \\
(37 \%)\end{array}$ & \\
\hline & Hemoglobin & $\begin{array}{c}24 \\
(53 \%)\end{array}$ & $\begin{array}{c}14 \\
(31 \%)\end{array}$ & $\begin{array}{c}7 \\
(15 \%)\end{array}$ & 0 & $\begin{array}{c}35 \\
(88 \%)\end{array}$ & $\begin{array}{c}4 \\
(10 \%)\end{array}$ & $\begin{array}{c}1 \\
(2 \%)\end{array}$ & 0 \\
\hline & Leucocytes & $\begin{array}{c}41 \\
(91 \%)\end{array}$ & $\begin{array}{c}2 \\
(4.4 \%)\end{array}$ & $\begin{array}{c}2 \\
(4.4 \%)\end{array}$ & 0 & $\begin{array}{c}13 \\
(32 \%)\end{array}$ & $\begin{array}{c}11 \\
(27 \%)\end{array}$ & $\begin{array}{c}14 \\
(35 \%)\end{array}$ & $\begin{array}{c}2 \\
(5 \%)\end{array}$ \\
\hline Late & Lungs & $\begin{array}{c}7 \\
(16 \%)\end{array}$ & $\begin{array}{c}23 \\
(51 \%)\end{array}$ & $\begin{array}{c}9 \\
(20 \%)\end{array}$ & 0 & $\begin{array}{c}8 \\
(20 \%)\end{array}$ & $\begin{array}{c}16 \\
(40 \%)\end{array}$ & $\begin{array}{c}11 \\
(27 \%)\end{array}$ & $\begin{array}{c}5 \\
(12 \%)\end{array}$ \\
\hline & Esophagus & $\begin{array}{c}36 \\
(80 \%) \\
\end{array}$ & $\begin{array}{c}5 \\
(11 \%) \\
\end{array}$ & $\begin{array}{c}4 \\
(8 \%) \\
\end{array}$ & 0 & $\begin{array}{c}30 \\
(75 \%)\end{array}$ & $\begin{array}{c}3 \\
(7 \%)\end{array}$ & $\begin{array}{c}7 \\
(17 \%)\end{array}$ & 0 \\
\hline
\end{tabular}

Treatment-related toxicities according to RTOG/EORTC are listed in Table 3. Acute esophagitis and incidence of neutropenia were higher with the concurrent than with sequential treatment arm. Grade 3 esophagitis was characteristic only for concurrent treatment, and it was the reason for radiotherapy interruption but no longer than 7 days. Secondary anaemia was frequent in the sequential treatment arm. Due to these results, adverse effects of both chemoradiotherapy arms were mild and moderate.

\section{Discussion}

Randomised phase III trial comparing sequential and concurrent administration of chemotherapy and radiation therapy for NSCLC has been published so far [4]. In the study of Furuse et al., the West Japan Group, chemotherapy combined cisplatin, vindesine and mitomycin $\mathrm{C}$. The total dose 
of radiotherapy was 56 Gy, and in the concurrent arm, was administered in a split-course schedule, with a rest period of 10 days. Median survival was significantly better with concurrent therapy than with sequential therapy $(16.5$ and 13.3 months, respectively; $p=0.0398)$. The $2-, 3-$, and 5-year survival rates were, respectively, $34.6 \%, 22.3 \%$ and $15.8 \%$ in concurrent arm, and $27.4 \%, 14.7 \%$ and $8.9 \%$ in the sequential arm. Radiation Therapy Oncology Group (RTOG) study 94-10 [5] compares sequential treatment with concurrent therapy in which the same dose of radiotherapy 63 Gy was administered during the two cycles of cisplatinvinblastine therapy, and with concurrent treatment using a bi-fractionated and accelerated irradiation 69.6 Gy combined with two cycles of cisplatinetoposide. The median survival rate in the concurrent treatment with cisplatin-vinblastine and standard radiotherapy was significantly better than that in the sequential arm (17 v 14.6 months; $p=0.046)$. The median survival rate in bi-fractionated irradiation was 15.2 months. The third study which supports the concomitant approach was from Zatloukal PV, 2004. Chemotherapy in both groups consisted of 4 cycles of cisplatin and vinorelbine every 4 weeks. Radiotherapy of 60 Gy was started in concurrent arm with the second cycle and in sequential arm 2 weeks after completion of the chemotherapy. Median survival time in the concurrent group was 16.8 months and in the sequential group was 12.9 months $(p=0.0216$, logrank test). Median time to progression was 11.9 in concurrent arm and 8.5 in sequential arm, respectively [6].

Our study compared sequential and concurrent chemoradiation therapy in locally advanced NSCLC. We found a benefit of concurrent therapy more than in previously listed trials, regarding overall and disease-free survival (19 vs 13; 16 vs 9 months), and the difference was significant with the log-rank test. When our study was designed, the cisplatin-etoposide combination was mostly used concurrently with radiotherapy [7]. Consolidation chemotherapy with two cycles of carboplatinetoposide was administered in the concurrent arm to balance the dose of platinum-based chemotherapy in the two arms. This consolidation chemotherapy administered after concurrent chemoradiotherapy seems promising regarding survival, as shown in the Southwest Oncology Group (SWOG) S9504 and Locally Advanced Multimodality Protocol (LAMP) studies [8], [9]. In the SWOG S9504 study, consolidation docetaxel following concurrent chemoradiotherapy, shown a median survival of 26 months and median progression-free survival of 16 months. Our concurrent-consolidation arm was shown similar results (OS 19 months and DFS 16 months). In our study, the local relapse rate was lower in the concurrent arm than in the sequential arm. In the RTOG 94-10 [5] study, local failure rates at 2 years were significantly lower in the concurrent arm. Thus it seems that the superior survival observed with concurrent treatment is associated with better local control.

We didn't observe major toxicity in our study. The incidence of grade 3 esophagitis was lower than in RTOG 94-10 study and the possibility for incidence reduction in our study was performing conformal 3D RT. The same findings were shown by Socinski et al., [10], [11]. The North Central Cancer Treatment Group (NCCTG) reported a phase I trial escalating the dose of RT with 3-D planning between 70 and 78 Gy [12], [13]. They defined maximum-tolerated dose as $74 \mathrm{~Gy}$ and reported an impressive median survival time of 37 months. The dose-limiting toxicities were mainly pulmonary. These results suggest that the dose and technical aspects of RT delivery are important in the combined modality approach for stage III NSCLC.

In conclusion, the statistically significant differences in survival were suggested that the concurrent chemotherapy and conformal threedimensional radiotherapy is the optimal strategy for patients with locally advanced NSCLC with acceptable toxicity rates. To date, it seems that more favourable outcomes may require than two cycles of full-dose systemic therapy, as well as chemotherapy concurrent with radiotherapy. In our study the dose-limiting toxicity, esophagitis was reduced by performing conformal radiotherapy

Conformal thoracic radiotherapy allows dose escalating and can probably improve survival and local control.

\section{References}

1. Le Chevalier T, Arriagada R, Quoix E, Ruffle P, Martin M, Tarayre M, Marie-José LT, Douillard JY, Laplanche A. Radiotherapy alone versus combined chemotherapy and radiotherapy in nonresectable non-small-cell lung cancer: first analysis of a randomized trial in 353 patients. Journal of the National Cancer Institute. 1991; 83(6):417-23. https://doi.org/10.1093/jnci/83.6.417 PMid:1847977

2. Non-small Cell Lung Cancer Collaborative Group. Chemotherapy in non-small cell lung cancer: a meta-analysis using updated data on individual patients from 52 randomised clinical trials. British Medical Journal. 1995:899-909. PMid:7580546 PMCid:PMC2550915

3. Friess GG, Baikadi M, Harvey WH. Concurrent cisplatin and etoposide with radiotherapy in locally advanced non-small cell lung cancer. Cancer treatment reports. 1987; 71(7-8):681-4.

PMid:3038313

4. Furuse K, Fukuoka M, Kawahara M, et al. Phase III study of concurrent versus sequential thoracic radiotherapy in combination with mitomycin, vindesine and cisplatin in unresectable stage III NSCLC. J Clinic Oncol. 1999; 17:2692-2699.

https://doi.org/10.1200/JCO.1999.17.9.2692 PMid:10561343

5. Curran Jr WJ. Long-term benefit is observed in a phase III comparison of sequential vs concurrent chemo-radiation for patients with unresectable stage III NSCLC: RTOG 9410. Proc Am Soc Clin Oncol. 2003; 22:621.

6. Zatloukal P, Petruzelka L, Zemanova M, Havel L, Janku F, 
Judas L, Kubik A, Krepela E, Fiala P, Pecen L. Concurrent versus sequential chemoradiotherapy with cisplatin and vinorelbine in locally advanced non-small cell lung cancer: a randomized study. Lung cancer. 2004; 46(1):87-98.

https://doi.org/10.1016/i.lungcan.2004.03.004 PMid:15364136

7. Albain KS, Crowley JJ, Turrisi III AT, Gandara DR, Farrar WB, Clark JI, Beasley KR, Livingston RB. Concurrent cisplatin, etoposide, and chest radiotherapy in pathologic stage IIIB nonsmall-cell lung cancer: a Southwest Oncology Group phase II study, SWOG 9019. Journal of clinical oncology. 2002;

20(16):3454-60. https://doi.org/10.1200/JCO.2002.03.055 PMid:12177106

8. Gandara DR, Chansky K, Albain KS, Leigh BR, Gaspar LE, Lara Jr PN, Burris H, Gumerlock P, Kuebler JP, Bearden III JD, Crowley $J$. Consolidation docetaxel after concurrent chemoradiotherapy in stage IIIB non-small-cell lung cancer: Phase II Southwest Oncology Group Study S9504. Journal of clinical oncology. 2003; 21(10):2004-10. https://doi.org/10.1200/JCO.2003.04.197 PMid:12743155

9. Choy H. Preliminary report of locally advanced multimodality protocol (LAMP): ACR 427: a randomized phase II study of three chemo-radiation regimens with paclitaxel, carboplatin, and thoracic radiation (TRT) for patients with locally advanced non small cell lung cancer (LA-NSCLC). Proc Am Soc Clin Oncol. 2002; 2002.

10. Wei X, Liu HH, Tucker SL, Liao Z, Hu C, Mohan R, Cox JD, Komaki R. Risk factors for acute esophagitis in non-small-cell lung cancer patients treated with concurrent chemotherapy and threedimensional conformal radiotherapy. International Journal of
Radiation Oncology Biology Physics. 2006; 66(1):100-7. https://doi.org/10.1016/i.ijrobp.2006.04.022 PMid:16839700

11. Socinski MA, Rosenman JG, Halle J, Schell MJ, Lin Y, Russo S, Rivera MP, Clark J, Limentani S, Fraser R, Mitchell W. Dose-escalating conformal thoracic radiation therapy with induction and concurrent carboplatin/paclitaxel in unresectable stage IIIA/B nonsmall cell lung carcinoma: a modified phase I/II trial. Cancer: Interdisciplinary International Journal of the American Cancer Society. 2001; 92(5):1213-23. https://doi.org/10.1002/10970142(20010901)92:5<1213::AID-CNCR1440>3.0.CO:2-0

12. Schild SE, McGinnis WL, Graham D, Hillman S, Fitch TR, Northfelt D, Garces YI, Shahidi H, Tschetter LK, Schaefer PL, Adjei A. Results of a phase I trial of concurrent chemotherapy and escalating doses of radiation for unresectable non-small-cell lung cancer. International Journal of Radiation Oncology Biology Physics. 2006; 65(4):1106-11. https://doi.org/10.1016/i.jirobp.2006.02.046 PMid:16730134

13. Bradley JD, Graham M, Suzanne S, Byhardt R, Govindan R, Fowler J, Purdy J, Michalski J, Gore E, Choy H. Phase I results of RTOG L-0117; a phase I/II dose intensification study using 3DCRT and concurrent chemotherapy for patients with inoperable NSCLC. Journal of Clinical Oncology. 2005; 23(16 suppl):7063. https://doi.org/10.1200/jco.2005.23.16 suppl.7063 